\title{
Long-term Outcome in Levothyroxine Treated Individuals with Subclinical Hypothyroidism and concomitant Heart Disease
}

\section{Mette Nygaard Andersen MD ${ }^{1}$ । mette.nygaard.andersen@gmail.com}

The authors have ne conflicts of interest to declare

Anne-Marie Schjerning Olsen MD PhD1, Jesper Clausager Madsen MD PhD², Søren Lund Kristensen MD PhD ${ }^{1}$, Jens Faber MD DMSc ${ }^{3,4}$, Christian Torp-Pedersen MD DMSc ${ }^{5}$, Gunnar H. Gislason MD PhD ${ }^{1,6,7}$, Christian Selmer MD PhD ${ }^{8}$

${ }^{1}$ Department of Cardiology, Gentofte University Hospital, Hellerup, Denmark, ${ }^{2}$ Elective Laboratory of the Capital Region, Copenhagen, Denmark, ${ }^{3}$ Department of Endocrinology, Herlev University Hospital, Herlev, Denmark, ${ }^{4}$ Faculty of Health Sciences, University of Copenhagen, Denmark, ${ }^{5}$ Department of Health Science and Technology, University of Aalborg, Denmark, ${ }^{6}$ The Danish Heart Foundation, Copenhagen, Denmark, ${ }^{7}$ The National Institute of Public Health, University of Southern Denmark, Copenhagen, Denmark, ${ }^{8}$ Department of Endocrinology, Amager and Hvidovre University Hospital, Copenhagen, Denmark.

\section{BACKGROUND}

Subclinical Hypothyroidism ( $\mathrm{SCH}$ ) is a common condition which can lead to impaired systolic and diastolic dysfunction. However, controversy remains over the potential benefits of levothyroxine treatment in patients with $\mathrm{SCH}$ and concomitant heart disease.

\section{AIM}

Examine the effects of levothyroxine treatment on all-cause mortality in patients with subclinical hypothyroidism and heart disease.

\section{METHODS}

In the present cohort study primary care patients aged 18 years and older with established heart disease (ischemic heart disease, heart failure or cardiac arrhythmia) who underwent thyroid function tests in $2000-2009$ were enrolled upon diagnosis of $\mathrm{SCH}$. Exclusion criteria included a history of thyroid dysfunction, thyroidrelated medication or medication affecting thyroid function.

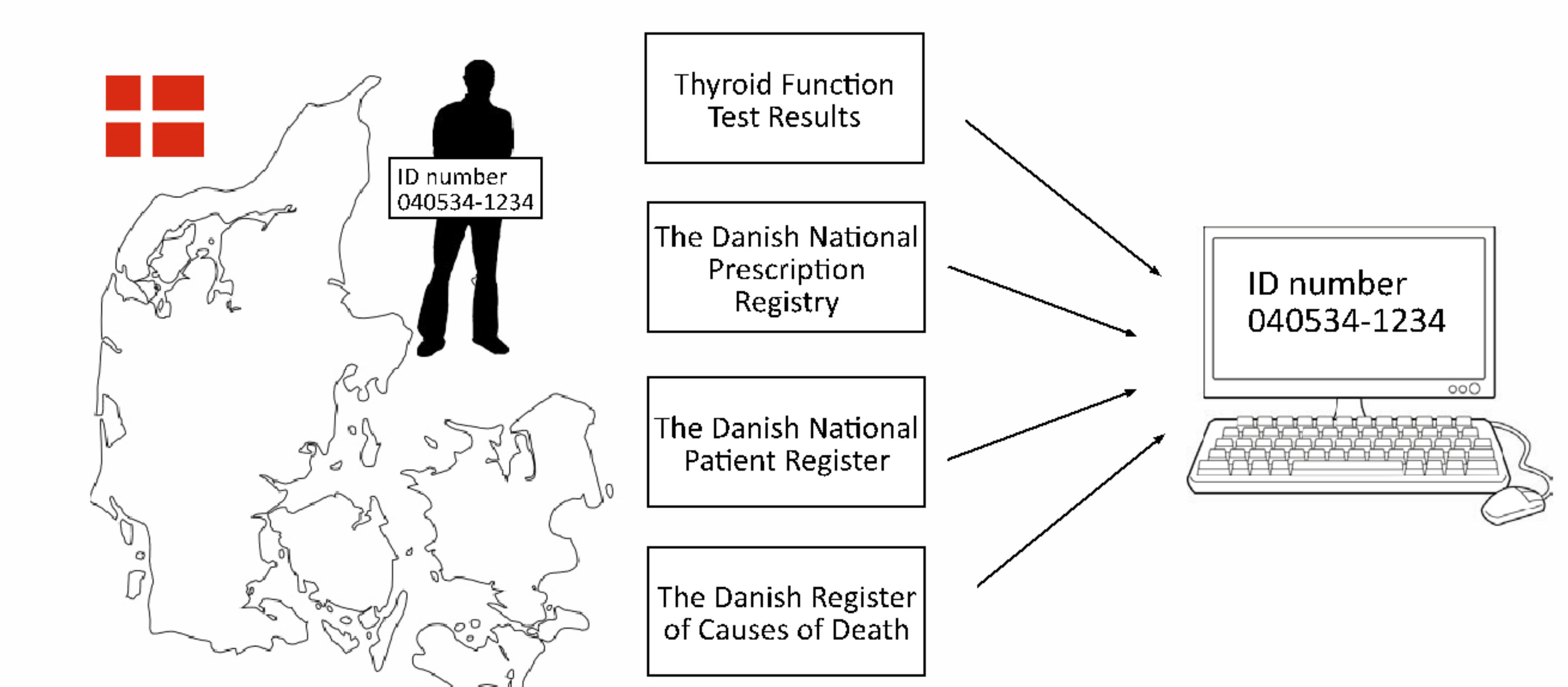

Patients were stratified according to cashed prescriptions of levothyroxine during a run-in period of 6 months. Risk of all-cause mortality was estimated as incidence rate ratio (IRR) by use of time-dependent Poisson regression models adjusted for age, gender and comorbidity, with patients not receiving levothyroxine as reference.

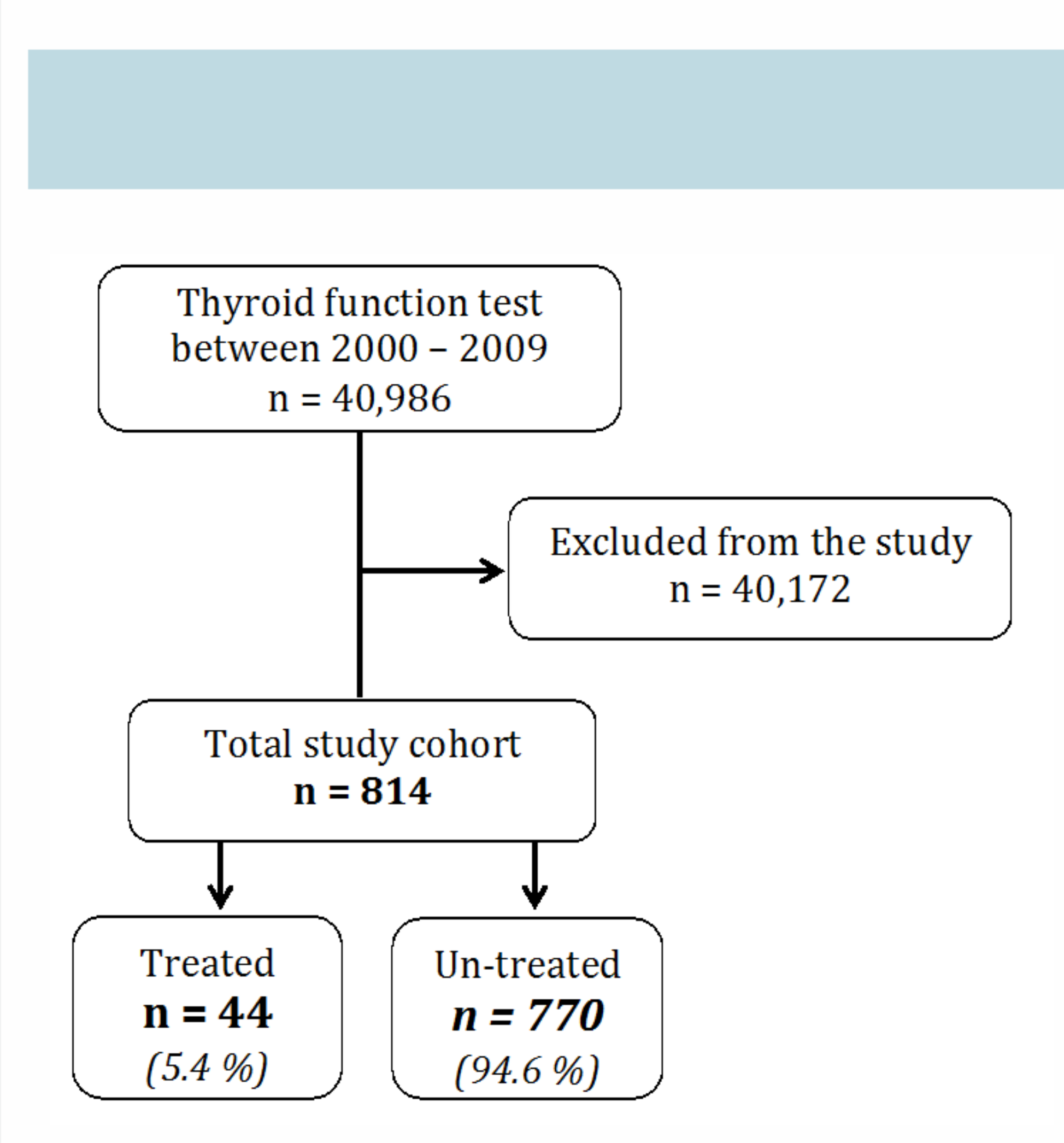

Figure 3: Defining the study population

\section{RESULTS}

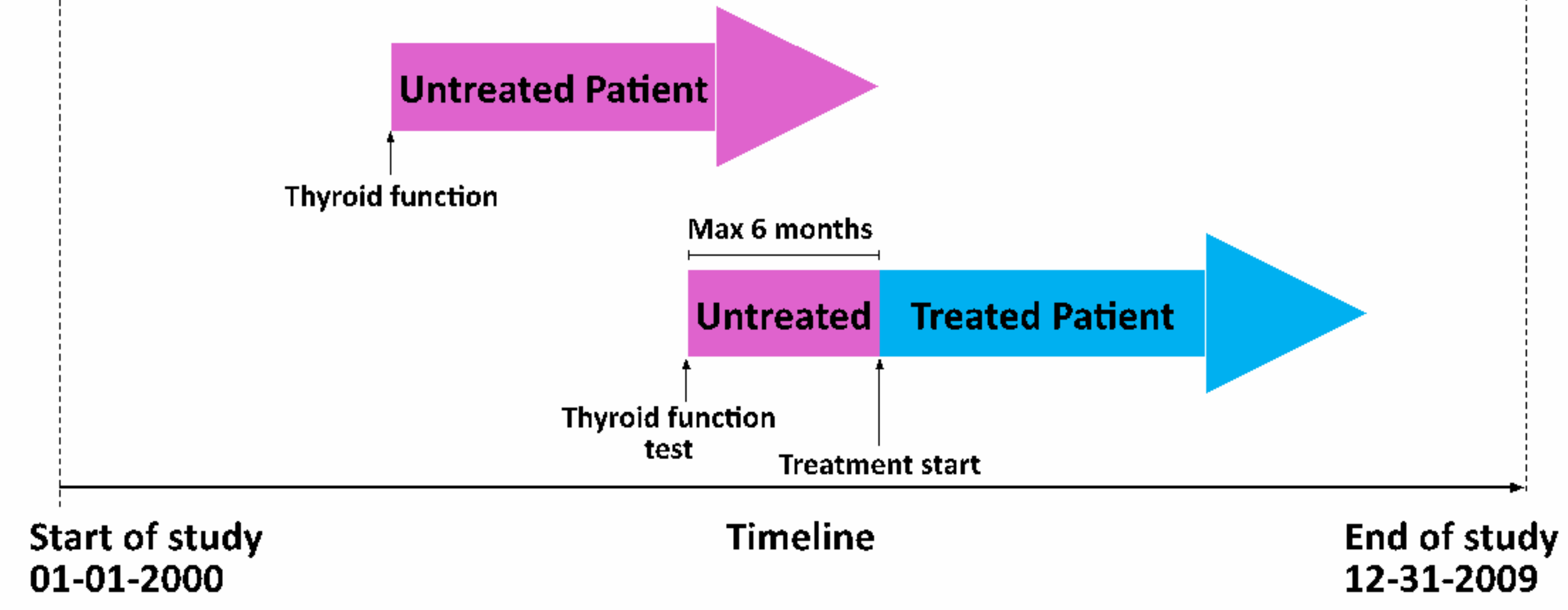

Figure 2: Study design

No significantly increased risk of all-cause mortality was found in patients treated with levothyroxine (IRR 1.06 [95\% Cl: 0.69-1.65]).

\section{CONCLUSION}

Levothyroxine treatment in patients with subclinical hypothyroidism and concomitant heart disease is not associated with a significant change in the risk of all-cause mortality in a real-world cohort study.

Follow-up:

During a median follow-up time of 5.1 years (IQR: $8.7-2.8$ ), 442 patients died $(54.3 \%)$.

Baseline characteristics:

- Mean age: 74.1 years $(S D \pm 13.5)$

- $65 \%$ were women

- No major distinctions in health

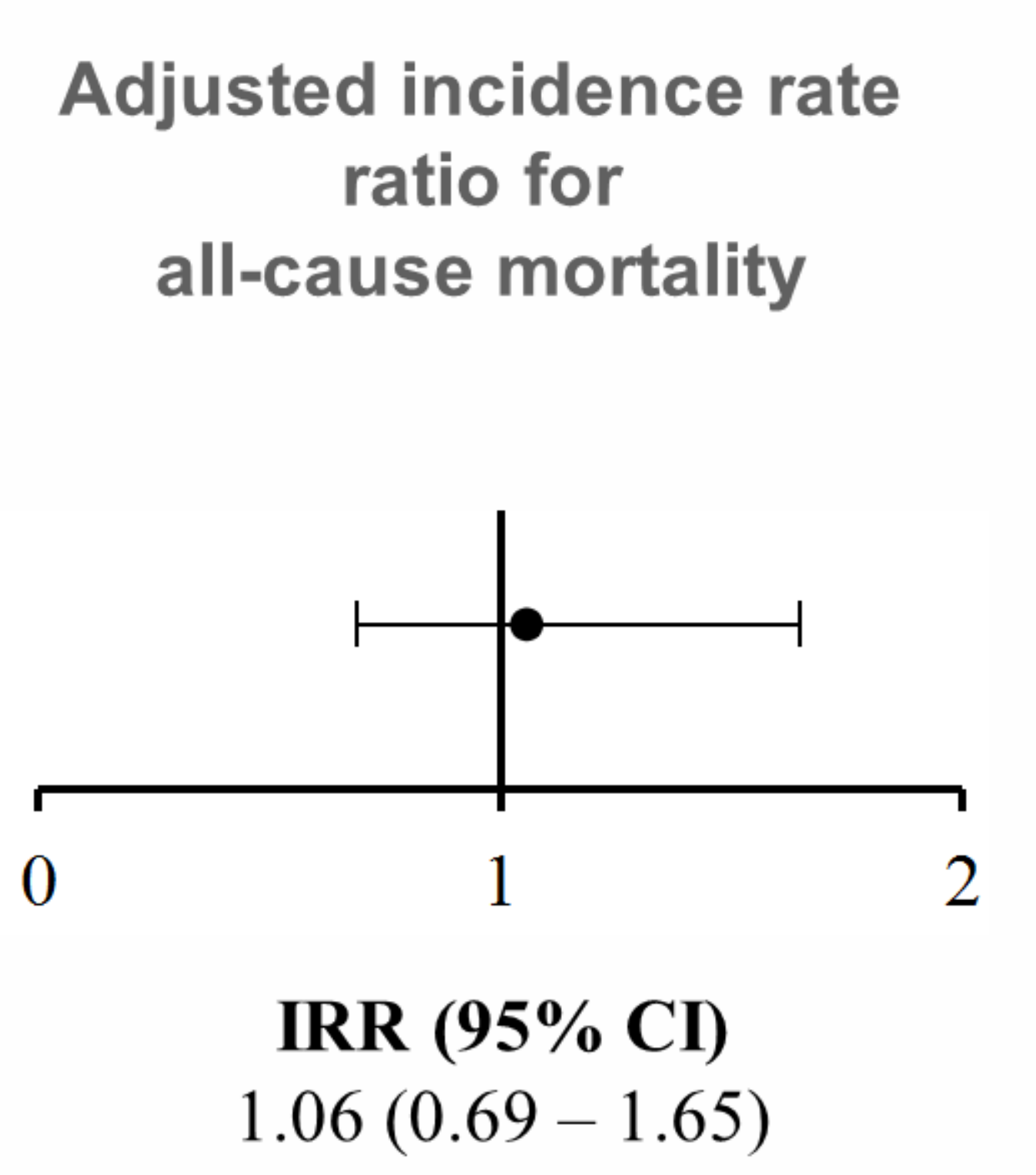

$1.06(0.69-1.65)$

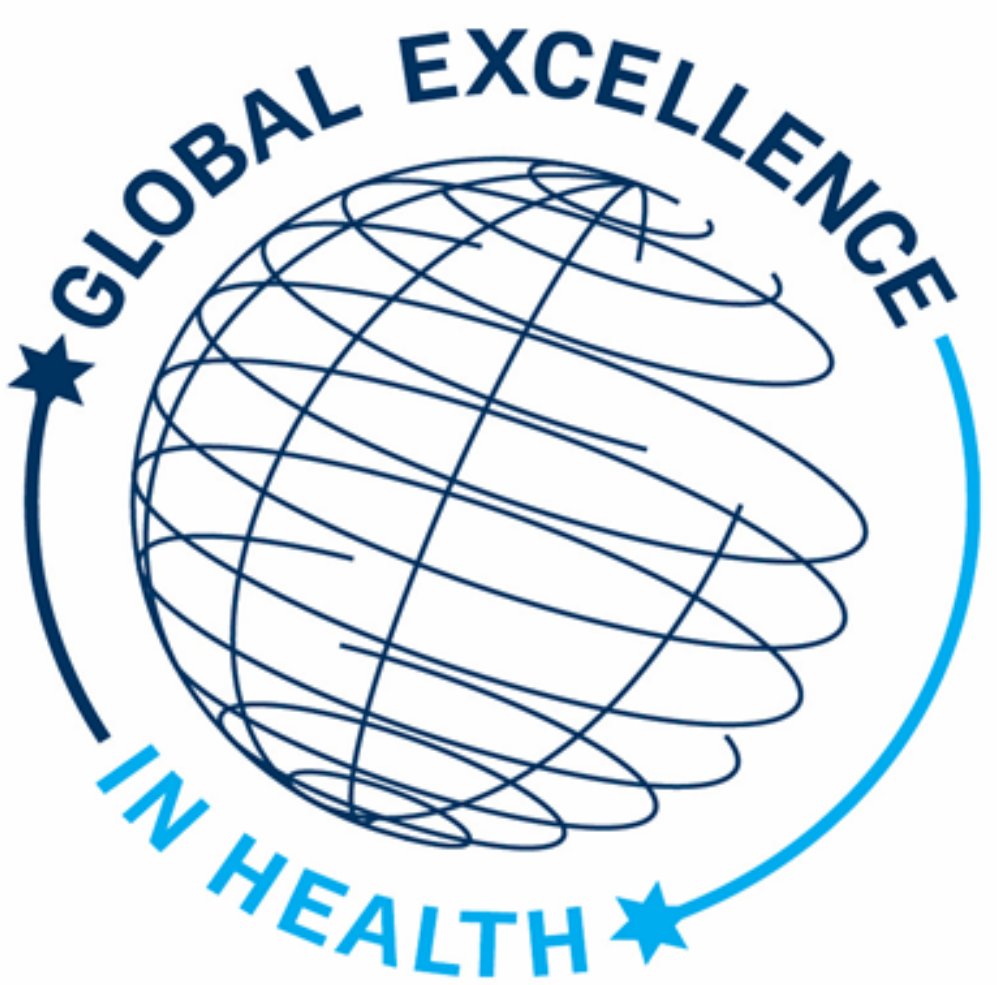

